\title{
PLASMA-ARC WELDING OF AN ISOTOPE CAPSULE*
}

\author{
G. M. Goodwin \\ Metals and Ceramics Division \\ and \\ B. F. Early \\ Isotopes Division \\ Oak Ridge National Laboratory \\ Oak Ridge, Tennessee 37830
}

\section{Abstract}

A certain thermoelectric generator uses a ${ }^{90} \mathrm{Sr}$ titanate fuel form contained in a heavy-walled capsule of Hastelloy $\mathrm{C}$, a nickel-base alloy with excellent strength, oxidation, and corrosion properties. The capsule design uses a threaded end cap, with a closure weld to ensure containment. Based upon maximum anticipated seawater corrosion rates, a minimum weld penetration of $0.055 \mathrm{in}$. is required.

Autogeneous gas tungsten-arc (GTA) welding has been used to produce the closure weld in a remote hot-cell environment; however, in the case of certain weldment designs and materials, the attainment of the required penetration by GTA welding presented problems.

A plasma-arc welding procedure was developed and successfully applied to four fueled capsules, achieving an average penetration of at least twice the minimum requirement. The plasma process was found to be relatively insensitive to several of the variables which greatly affect penetration in the GTA process.

The advantages of the plasma welding process for this application include (I) ease of alignment - a low-current pilot arc can be used to align the torch with the weld joint prior to welding, (2) freedom from stubout and possible tungsten inclusions, (3) freedom from critical arc-length considerations, and, most importantly, (4) increased penetration, proviaing a factor of safety over the minimum penetration requirement.

\section{Introduction}

\section{Thermoelectric Generators}

Isctopically fueled thermoelectric generators are used as highly reliable sources of electric power in areas of limited access in undersea, space, and remote terrestrial applications. A typical terrestrial system is shown in Figure l. The decay heat from a radioactive fuel is used to heat thermoelectric elements, producing usable power for long times, limited by the half-life of the isotopic fuel form in the durability of the generator components.

*Research sponsored by the U.S. Atomic Energy Commission under contract with the Union Carbide Corporation. 


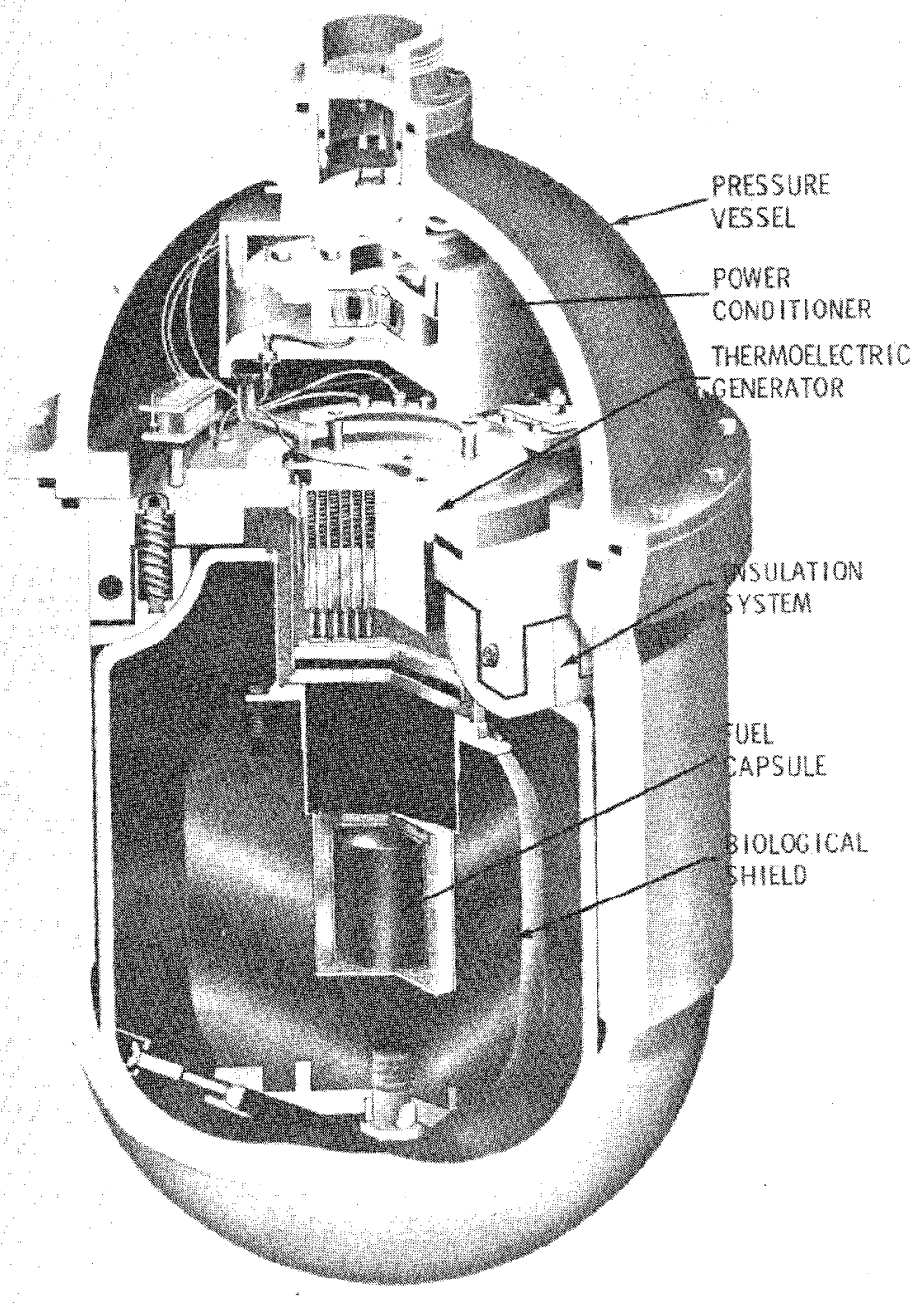

Fig. I. Cutaway View of Thermoelectric Generator. 
Strontium-90 is a relatively inexpensive, commonly used radioisotopic fuel. Its bremstrahlung radiation is such that it must be handled remotely during fabrication of the fuel and welding of the capsule. The chemical form of strontium most commonly used is the titanate, ${ }^{9} \mathrm{Sr}^{1} \mathrm{iO}_{3}$ or ${ }^{90} \mathrm{Srr}_{2} \mathrm{LiOH}_{4}$.

Since these systems are designed to operate for extended times in potenlially hostile environments such as seawater and since the release of fuel material to the surroundings must, of course, be avoided, the fuel material is encapsulated in a suitable container designed to withstand the most rigorous environment for the effective life of the fuel. Seal welding of the fuel capsule j.s thus a critical step in the construction of a thermolectric generator.

Haslelloy $C$ is a commonly used containment material because of its compatibility with the various fuel forms and its excellent strength, oxidation, and corrosion behavior.

Remote Ilandling

As mentioned above, ${ }^{90} \mathrm{Sr}$ isotopic fuels, because of their intense radiation, must be handled remotely during all stages of the fabrication of a thermoelectric generator, until such time that the fueled assembly is installed within the biological shield (see Figure 1). Seal welding of the fueled capsule must thus be accomplished remotely. A typical remote welding operation is shown in Figure 2. The welding power supply is situated outside the cell and connected to the torch, fixturing, etc., through the cell wall. All operations within the cell must be performed using master-slave manipulators, as shown in the figure. Such operations as alignment of the torch over the weld joint and setting of the necessarily precise electrode-to-work distance are complicated hy both the limited visibility and the restricted manipulative ability. Such operations must be viewed through 2 to 4 ft of radiation shielding glass using monoculars, jig transits, periscopes, and whatever other optical aides are necessary. Nondestructive inspection of a completed weld is also obviously made greatly more difficult, a subject outside the scope of this paper. It should be noted, however, that all other things being ecual, a welding process with a smaller number of critical variables to be controlled in-cell is definitely more desirable.

\section{Material}

The material used for the major portion of this experiment was Hastelloy $C$, the composition of which is given below:

\begin{tabular}{|c|c|c|c|}
\hline Element & Content (wt \%) & Eliement & Content (wt $\%)$ \\
\hline $\mathrm{Cr}_{r}$ & 15.15 & $\operatorname{Mn}$ & 0.51 \\
\hline$W$ & 3.85 & $\mathrm{~V}$ & 0.04 \\
\hline $\mathrm{Fe}$ & 5.85 & Mo & 15.65 \\
\hline $\mathrm{C}$ & 0.06 & $\mathrm{P}$ & 0.010 \\
\hline $\mathrm{Si}$ & 0.30 & S & 0.005 \\
\hline Co & 1.00 & $\mathrm{Ni}$ & BAJ \\
\hline
\end{tabular}

Several other heats were checked for penetration variability with the plasma-arc welding process, and since there were no significant variations, are not reported here. 


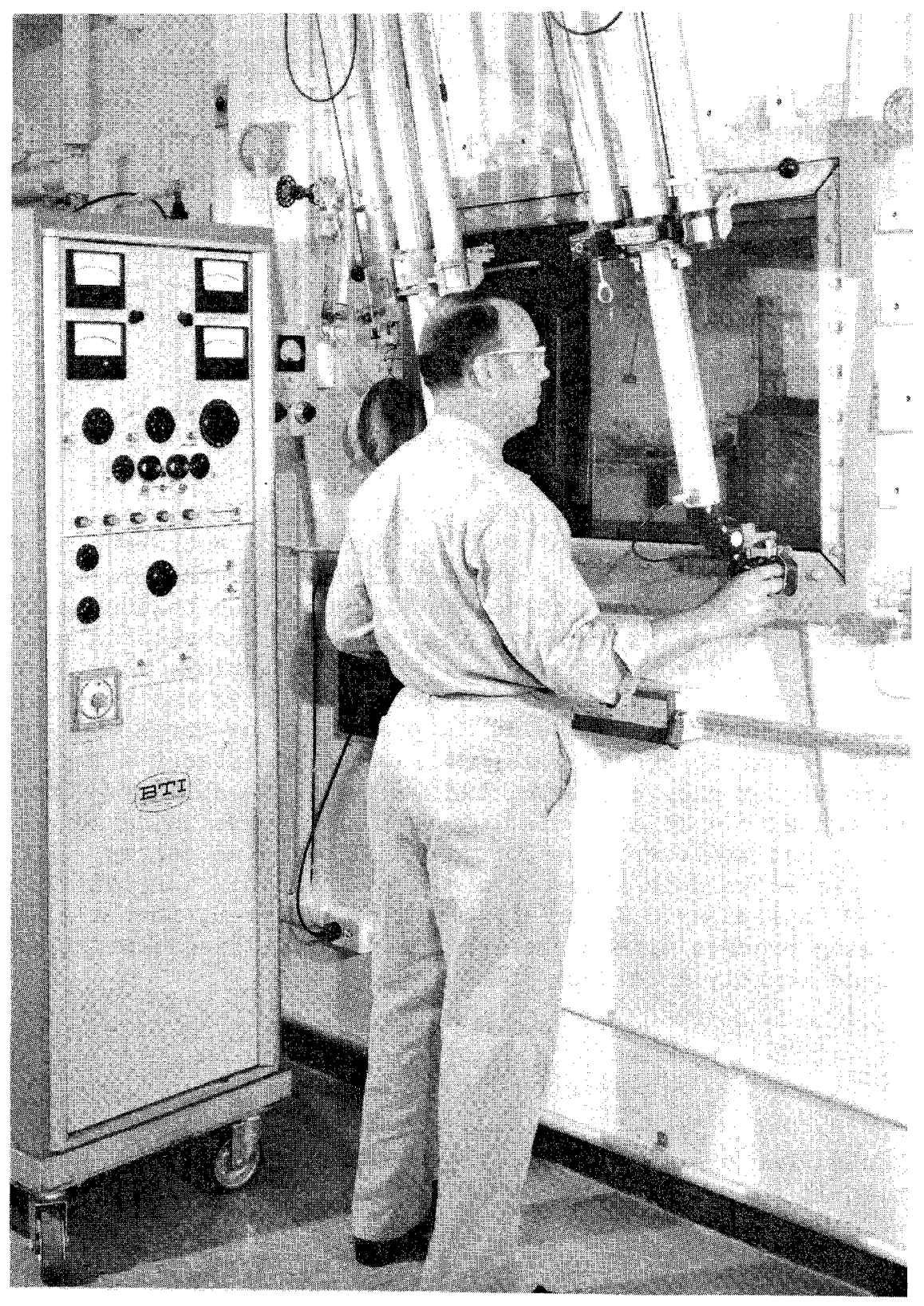

Fig. 2. A Typical Hot-Cell Welding Operation. Note that Fxcept for Setting the Weld Programmer, All Operator Functions are Performed Using Master-Slave Manipulators. 


\section{Welding Processes}

\section{Gas Tungsten-Arc}

Figure 3 illustrates schematically the gas tungsten-are and plasma-arc welding processes. The gas tingsten-arc welding process utilizes a nonconsumable tungsten electrode and a highly ionized plasma of inert gas, usually argon, which is introduced around the electrode. Heat is supplied to the material being welded, for the most part, by the kinetic energy of current carriers impinging on the material surface. The electrode-to-work aistance (or arc length) is thus a critical variable having a slrong effect on weld penetration.

\section{Plasma-Arc}

The plasma-arc welding process (1) utilizes a similar plasma; but greatly enhances its penetrating ability by causing it to pass through a water-cooled coppcr orifice, thereby constricting the plasma. Additional gas shielding to prevent metal oxidation is introduced outside and around the orifice. Due to the "focusing" effect of the orifice, electrode-to-work distance is much less critical; for most applications, variation from $1 / 8$ to $3 / 8$ in. has little effect.

The plasma welding process is usually operated in what is termed the "keyholing" mode for welding thin platc or sheet. Using this mode, the arc forces, combined with the liquid metal surface tension, maintain a "keyhole" in the weld pudale as shown in Figure 4. Full penetration is ensured, and the keyhole is eliminated at the termination of the weld by gradually decreasing current and/or plasma gas flow rate.

In the seal-welding application described in this report, the plasma-arc process is operated in the blind (non-full-penetration) mode. Welding parameters must be developed to avoid entrapped voids or cold-shuts. The extreme force of the plasma (which, of course, is the reason for its enhanced penetration) causes a depression in the puddle surface, and if not properly controlled, this forcc can rcsult in "gouging" and the subsequent entrapment of voids as the liquid fails to properly fill the crater behind the advancing arc.

\section{Electron Beam}

A third welding process which should be mentioned as an alternative technique is the electron beam process. (2) Greatly enhanced penetration is obtainable, but the process has the inherent disadvantage that it must be done in hard vacuum, a requirement that entails installation and maintenance of complex equipment in a hotccll application.

Welding Development

The fuel containers are right circular cylinders, 3 3/4 in. in diameter by $105 / 16 \mathrm{in.} \mathrm{high,} \mathrm{with} \mathrm{a} \mathrm{wall} \mathrm{thickness} \mathrm{of} 0.36 \mathrm{in.}$ The end caps are $3 \mathrm{l} / 8 \mathrm{in}$. diam $\times 15 / 16 \mathrm{in.}$ thick and threaded with 16 threads per inch. Test pieces were of identical geometry except that their height was restricted to 1 1/4 in. to conserve material. (In some preliminary samples, threads were omitted.) 
TIG TORCH

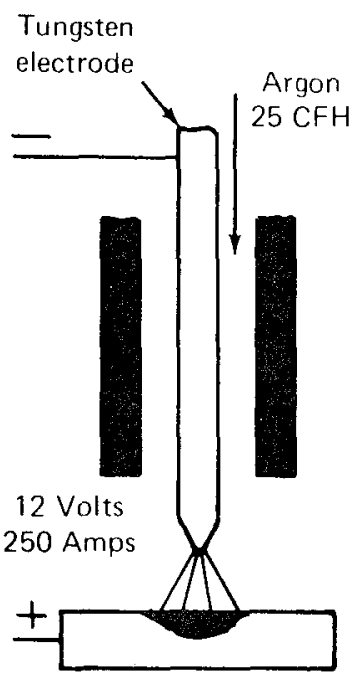

PLASMA ARC TORCH

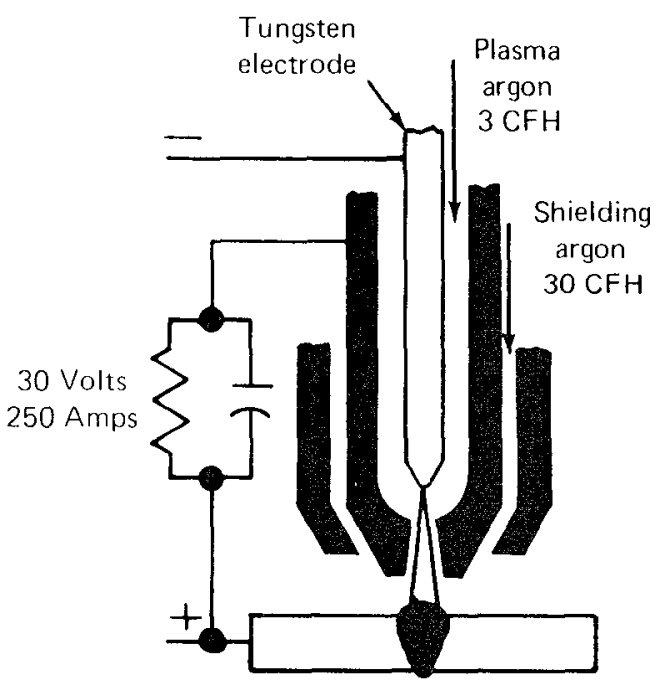

Fig. 3. Schematic Comparison of the Gas Tungsten-Arc and PlasmaArc Welding Processes. 


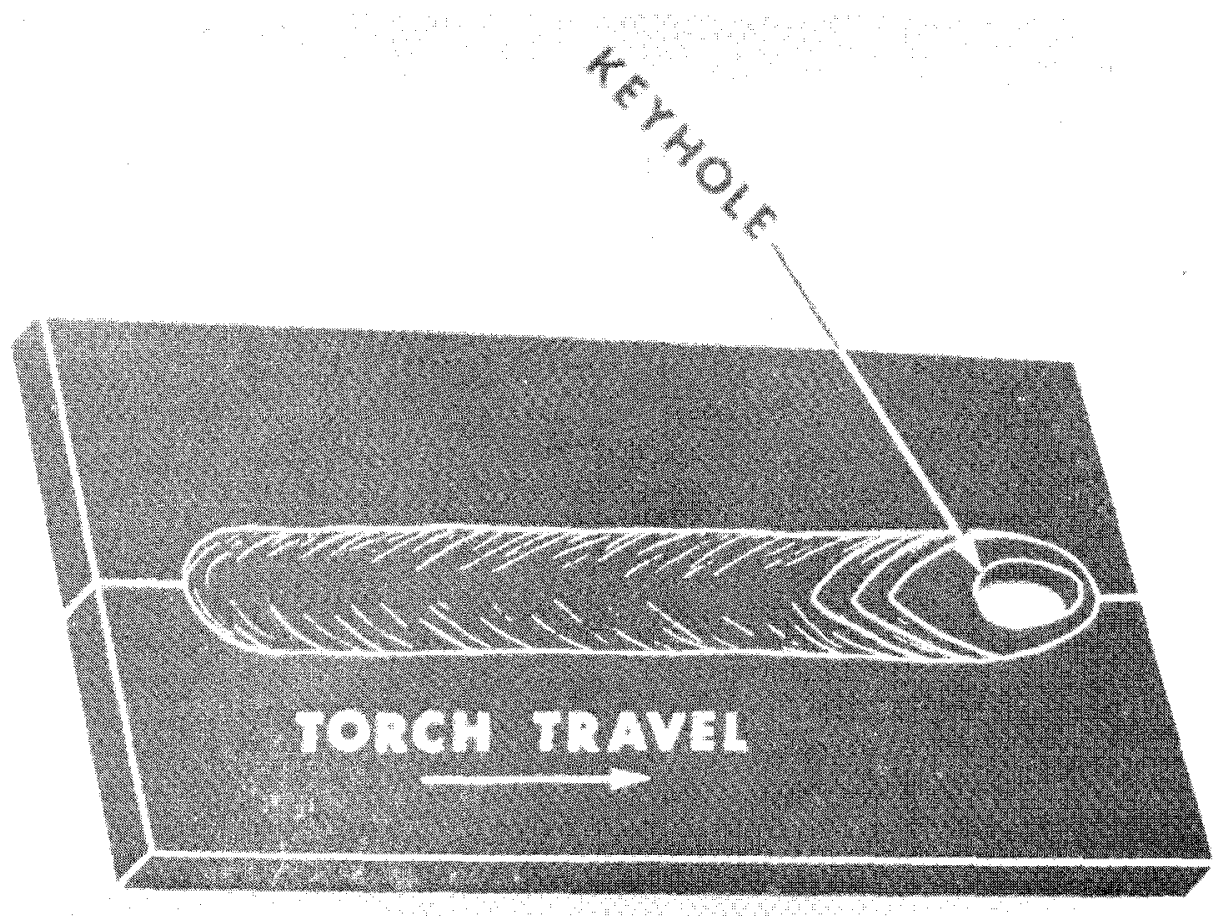

Fig. 4. Representation of Keyhole Effect Usually

Associated with Fuli-Penetration Plasma-Arc Welding. 
Containers and test pieces were both rotated under a stationary torch with a variable speed motor-driven chuck, as shown in Figure 5.

Gas tungsten-arc welds were produced using a commercial GTA torch coupled with a 400-amp de weld programmer.

Plasma welds were produced with a commercial plasma welding torch coupled with a 400-amp de weld programmer.

All developmental welds were made out-of-cell with the above described equipment, which was subsequently installed in the hot-cell area for welding of the fueled assemblies. Developmental welds were destructively examined by sectioning and metallography.

The range of experimental variables invastigated is shown in Table 1 for the plasma process. Gas-tungsten arc welds were made only for comparative purposes, and the conditions used are shown on the figures. Due to process limitations, not all combinations of the variables shown in Table 1 were studied.

TABLE 1. CONDITIONS USED FOR DEVELOPMENTAL PLASMA WELDS IN HASTELLOY C

\begin{tabular}{llr}
\hline \multicolumn{1}{c}{ Variables } & \multicolumn{1}{c}{ Range } & Final \\
\hline & $140-175$ & 140 \\
Current, A & $10-15$ & 10 \\
Travel speed, in./min & $2.4-3.2$ & 2.4 \\
Plasma gas, ft ${ }^{3} / \mathrm{hr}$ & $3 / 32,1 / 8$ & $1 / 8$ \\
Oririce diameter, in. & 24 (constant) & 24 \\
Shield gas, ft ${ }^{2} / \mathrm{hr}$ & $5 / 16$ (constant) & $5 / 16$ \\
Electrode-to-work distance, in. & & \\
\hline
\end{tabular}

Figure 6 illustrates the modest improvement in penetration that can be obtained in the GTA process by variation of the shielding gas composition. Although each of the welds illustrated meets the required 0.055-in.-minimum penetration requirement in this instance, there is little margin available to accommodate unexpected penetration variability.

A comparison of the results obtained using the two welding processes at equal current levels is shown in Figure 7. Note that the plasma-arc process achieves over twice the penetration of the gas tungsten-arc process, with approximately the same surface width.

Approximately 25 welds were produced using permutations of the conditions shown in Table 1 with the aim at arriving at a compromise between maximized penetration (high current, slow travel, high plasma gas flow, small orifice) and smallest probability of entrapped voids (low current, slow travcl, low plasma gas flow, large orifice). The final conditions selected are also shown in Table 1 , and their results are compared with the GTA conditions which had been used previously in Figure 8 . Note that the plasma process gives nearly three times the required penetration. A completed test sample is shown in Figure 9. 


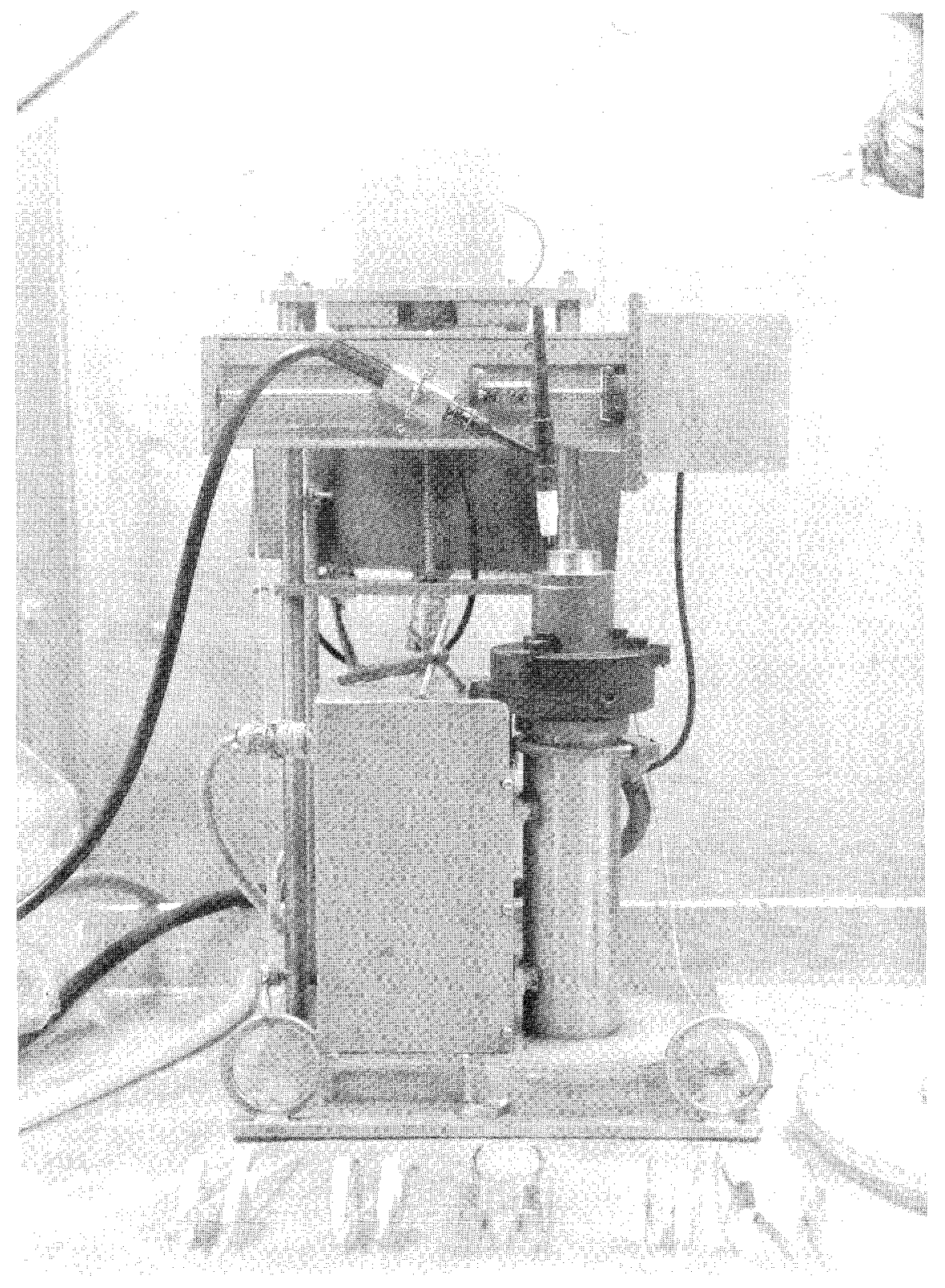

Fig. 5. A Typical Hot-Cell GTA Welding Setup. 


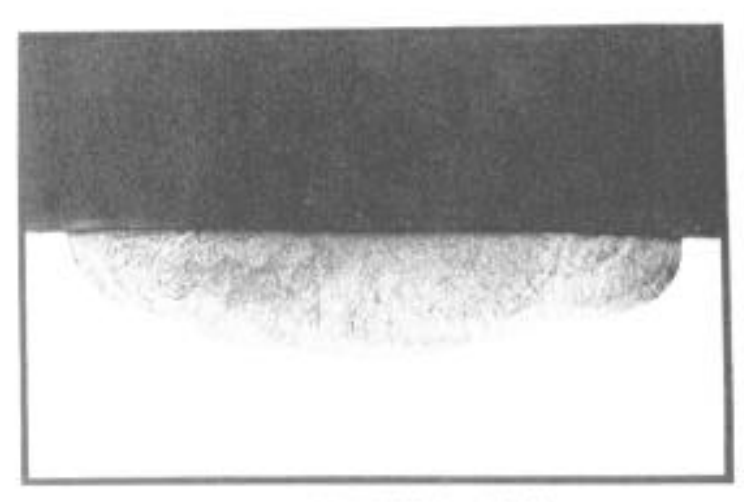

$100^{\circ}$ S ARGON, PENEIRADON -30 wih

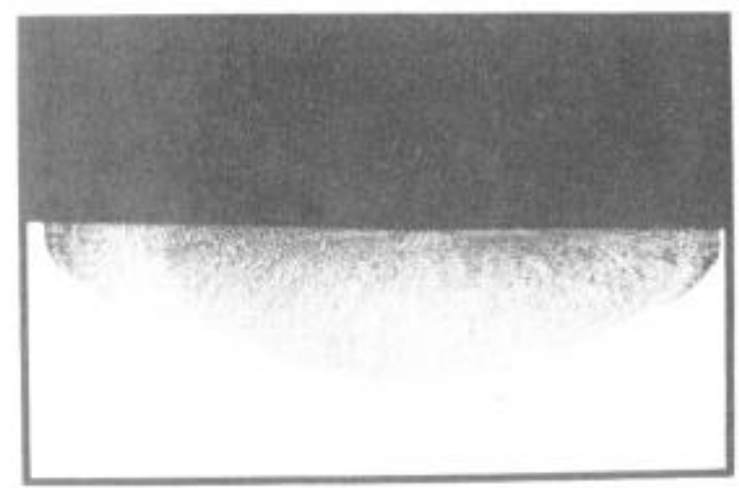

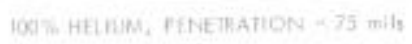

Fig. 6. Effect of Shielding Gas on GTA Welds in Hinstelloy C at 170 amp.

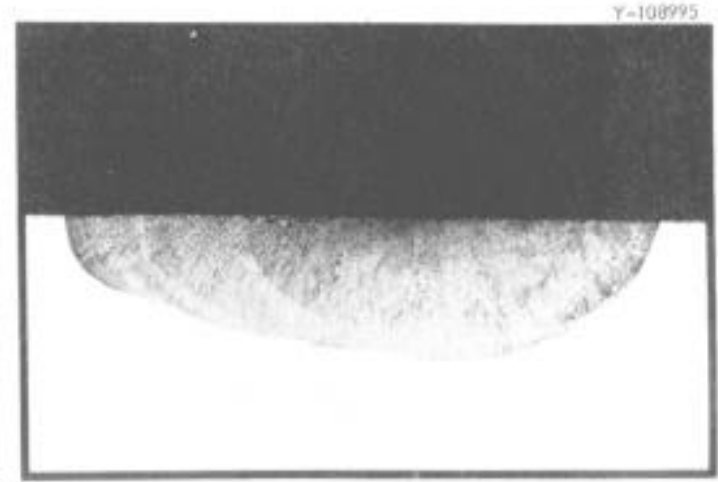

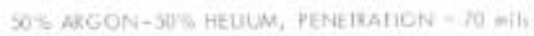

FFFECT OF SHIELDING GAS ON GIA WELDS IN HASTELIOY C AT INO IMOH 


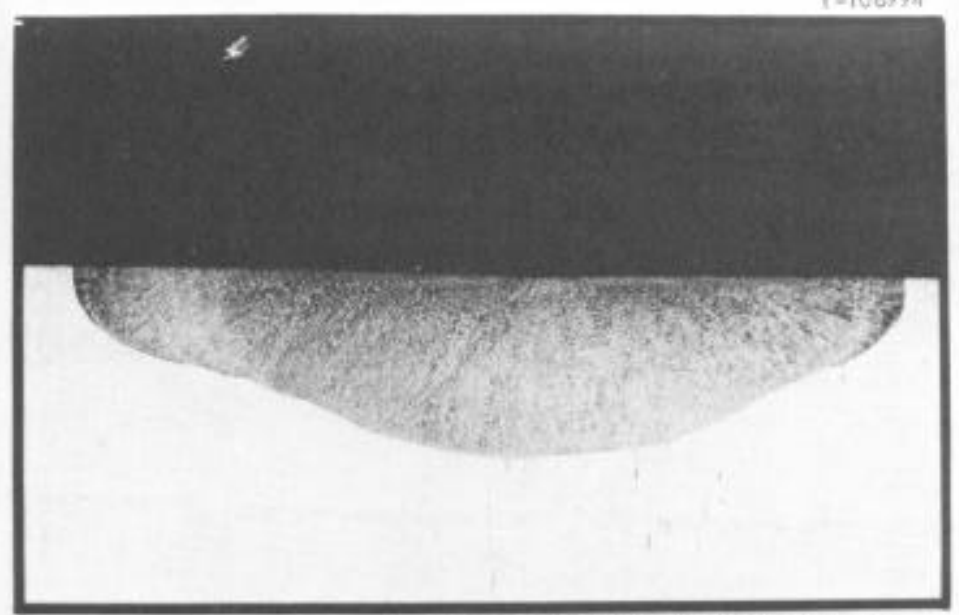

GIA PROCESS WITH HELIUM SHIELD GAS, PENETRATION $=75$ mils

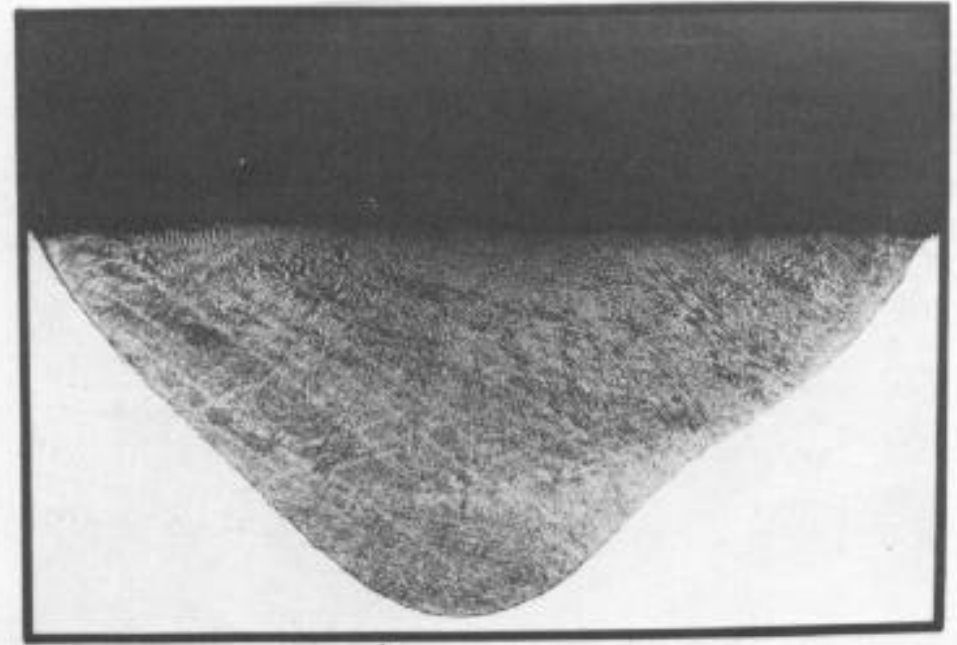

PLASMA ARC PROCESS WITH ARGON SHIELD GAS, PENETRATION $=160 \mathrm{mils}$

Fig. 7. Gas Tungsten-Arc Process with Helium Shield Gas vs Plasma-Arc Process with Argon Shield Gas in Hastelloy C at 170 amp. 


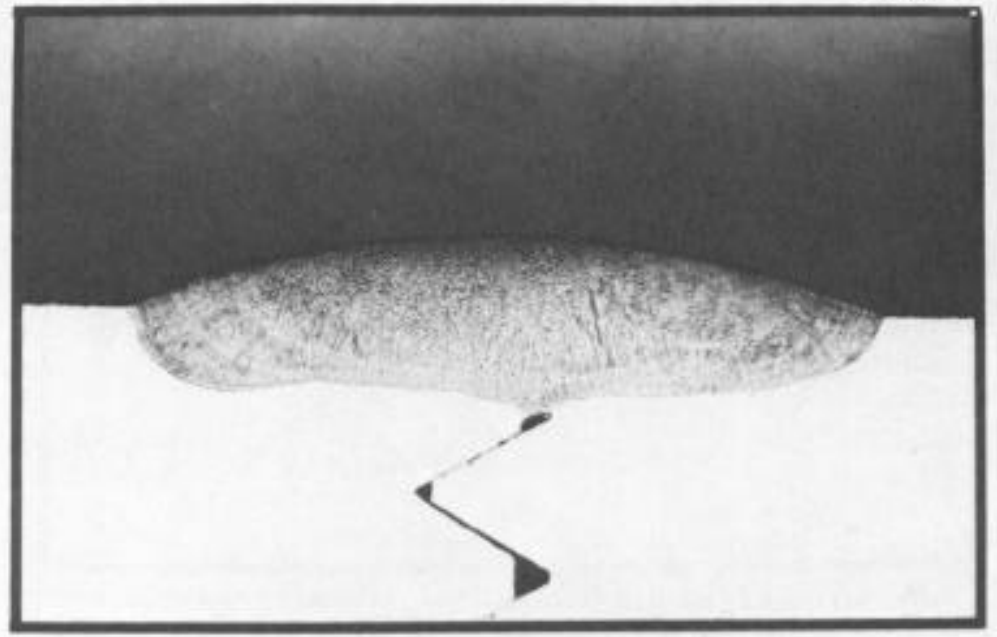

(A) GTA WELDING PROCESS AT 170 amps, PENETRATION $=65$ mils

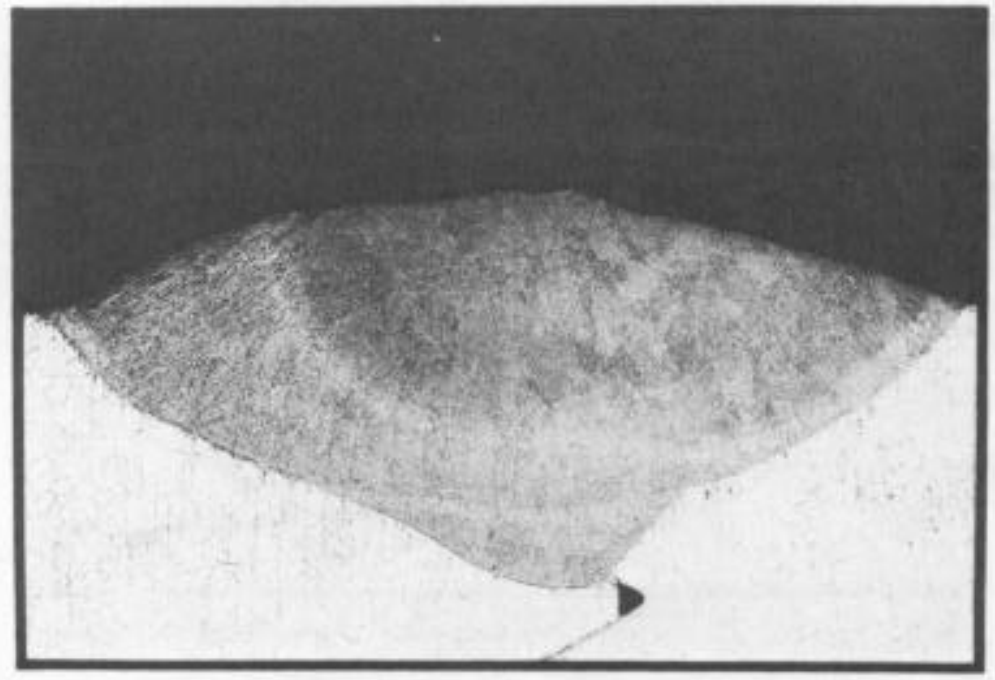

(B) PLASMA ARC WELDING PROCESS AT $140 \mathrm{amps,} \mathrm{PENETRATION}=156 \mathrm{mils}$

Fig. 8. Capsule Welds Made by Gas-Tungsten and Plamsa-Arc Welding Processes. 


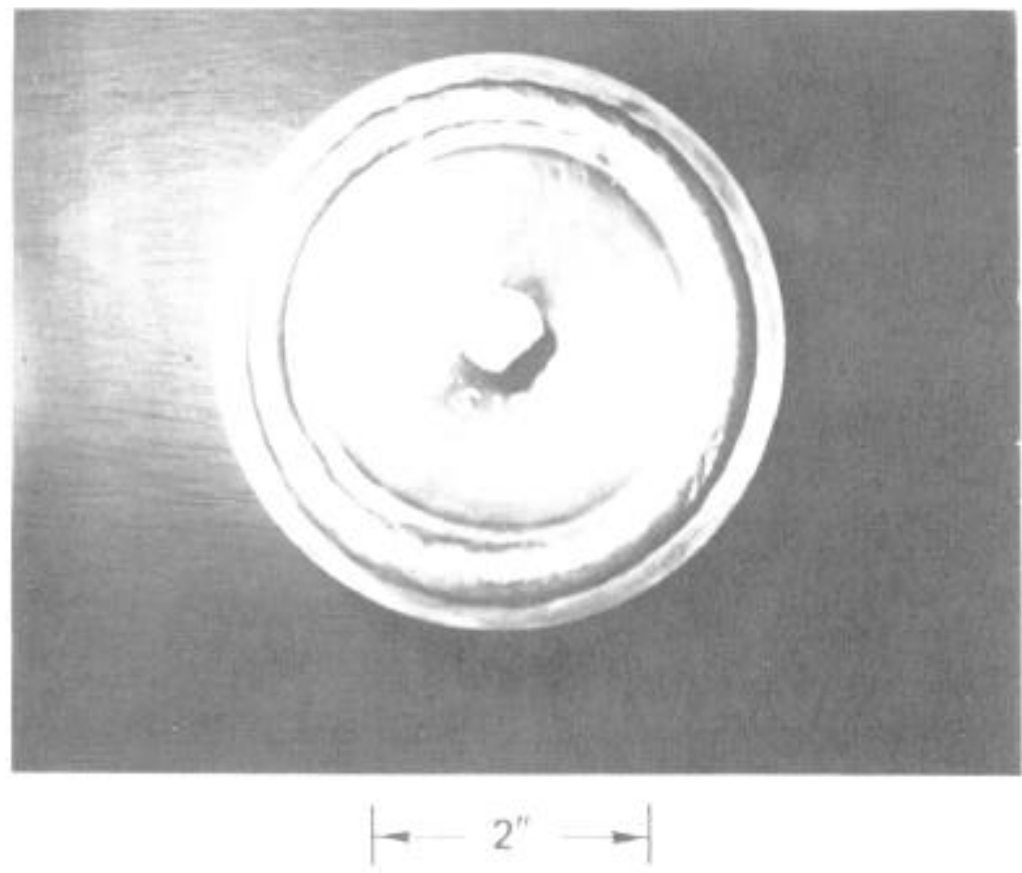

Fig. 9. Pleama-Are Wolied Test Sample of Hadelloy C Material. 
Several test pieces were welded with approximately $600^{\circ} \mathrm{F}$ preheat to approximate the condition to be expected in the fueled capsules; a very minor increase in penetration was noted with no other apparent changes. Since an increase in penetration is, of course, desirable, one could assume that performing the developmental welds without preheat was a conservative course to follow.

Following the welding development, the equipment was transferred to the hot-cell location and four fueled capsules were successfully welded. Both preweld and postweld test specimens were welded and destructively examined before and after each of the fueled capsule welds to ensure reliability in the final product. These capsules are now in service.

\section{Conclusions}

The plasma-are welding process was found to be a highly reliable technique for hot-ce $\perp$ remote welding of an isotopic fuel capsule. The advantages of the plasma welding process for this application include:

1. Easc of alignment - A low-current pilot arc can be used to align the torch with the weld joint prior to welding.

2. Freedom from stubout and possible tungsten inclusions - The plasma process does not use an exposed tungsten electrode as does the GTA process.

3. Relative freedom from arc-length considerations - Torch-to-work distance can vary from approximately $1 / 8$ to $3 / 8$ in. without appreciable effect, and, most importantly,

4. Increased penetration - Due lo lhe inherent characteristics of the plasmaarc welding process, sufficient penetration could easily be achieved to provide a factor of safety over the minimum penetration requirement.

After a modest welding development program, the process was used to successfully weld four fueled capsules. 


\section{$\underline{\text { References }}$}

1. WeZding Handbook, 6th edition, Section 3B, Chapter 54, American Welding Society, New York, 1971.

2. R. W. Gunkel, R. G. Donnelly, and G. M. Slaughter, "Electron Beam Welaing of Strontium-Fueled Capsules," WeZding J. (N.Y.), 48(12): 950-955 (December 1969). 